\title{
Dissolution of uranium dioxide in nitric acid media: what do we know?
}

\author{
Philippe Marc ${ }^{1}$, Alastair Magnaldo ${ }^{1, *}$, Aimé Vaudano ${ }^{1}$, Thibaud Delahaye ${ }^{2}$, and Éric Schaer ${ }^{3}$ \\ ${ }^{1}$ CEA, Nuclear Energy Division, Research Department of Mining and Fuel Recycling Processes, Service of Dissolution and \\ Separation Processes, Laboratory of Dissolution Studies, 30207 Bagnols-sur-Cèze, France \\ ${ }^{2}$ CEA, Nuclear Energy Division, Research Department of Mining and Fuel Recycling Processes, Service of Actinides Materials \\ Fabrication, Laboratory of Actinide Conversion Processes, 30207 Bagnols-sur-Cèze, France \\ ${ }^{3}$ Laboratoire Réactions et Génie des Procédés, UMR CNRS 7274, University of Lorraine, 54001 Nancy, France
}

Received: 16 March 2016 / Received in final form: 15 November 2016 / Accepted: 14 February 2017

\begin{abstract}
This article draws a state of knowledge of the dissolution of uranium dioxide in nitric acid media. The chemistry of the reaction is first investigated, and two reactions appear as most suitable to describe the mechanism, leading to the formation of monoxide and dioxide nitrogen as reaction by-products, while the oxidation mechanism is shown to happen before solubilization. The solid aspect of the reaction is also investigated: manufacturing conditions have an impact on dissolution kinetics, and the non-uniform attack at the surface of the solid results in the appearing of pits and cracks. Last, the existence of an autocatalytic mechanism is questionned. The second part of this article presents a compilation of the impacts of several physico-chemical parameters on the dissolution rates. Even though these measurements have been undertaken under a broad variety of conditions, and that the rate determining step of the reaction is usually not specified, general trends are drawn from these results. Finally, it appears that several key points of knowledge still have to be clarified concerning the dissolution of uranium dioxide in nitric acid media, and that the macroscopic scale which has been used in most studies is probably not suitable.
\end{abstract}

\section{Introduction}

Recycling has been chosen for decades by several countries for treating their spent nuclear fuel. This way of treatment has been demonstrated to be environmentally efficient, by allowing a maximum use of the energetical potential of uranium [1].

Several processes have been developed for recycling nuclear spent fuels, most of them being based on hydrometallurgy. Among these hydrometallurgical processes, the PUREX process is the most used at industrial scale, enabling the separation and recovery of uranium and plutonium from spent nuclear fuels [2,3]. In this process, as in most of the other hydrometallurgical processes, the head-end step consists in dissolving uranium dioxide based spent nuclear fuels (UOX) in a hot concentrated nitric acid medium.

Given that UOX spent fuels still contain about $96 \%$ of uranium dioxide [4], it is the dissolution of this element which mainly governs the dissolution of the overall fuel.

\footnotetext{
* e-mail: alastair.magnaldo@cea.fr
}

Due to its importance, the dissolution of spent nuclear fuels in nitric acid media has been widely studied during the past decades. But surprisingly, the number of articles dealing specifically with the dissolution of uranium dioxide in nitric acid media appears to be pretty small in comparison to its importance in the process, and most of the articles which can be found in the literature mainly focus on the dissolution rates of this material, or only on a part of the mechanism taking place. The ability of uranium dioxide to easily dissolve when contacted with nitric acid is probably one of the reasons, with the complexity of the phenomena involved, why little interest has been devoted to understanding the mechanisms of this reaction. However, the kinetics of this reaction define the size, and then the cost, of the process installation for a given production rate. More specifically in the nuclear field, they also influence the hold-up of nuclear products in the headend step, and thus the criticality issues.

Another problem is that the studies reported in the literature have been realized under a broad variety of conditions. For example, solids are usually made by sintering, but the condition of this sintering varies from a study to another, just as the geometrical characteristics of 
the resulting solids (spheres, pellets, powders). As a result, the mechanisms taking place remain poorly understood. It appears that this lack of knowledge limits the capability to develop efficient models of the dissolution process, and that any change in the operating conditions for industrial dissolution is complicated to predict.

This paper presents a compilation of the most relevant studies on the dissolution of uranium dioxide in nitric acid media. Despite the difficulties mentioned above, the cross referencing enables to make a state of the art of the understanding of this reaction according to literature, to draw conclusions on some parts of the mechanism, and finally, to enlight the gaps which still need to be filled concerning the understanding of the mechanisms and the kinetics of this reaction.

\section{Reaction of uranium dioxide with nitric acid}

The reaction of uranium dioxide $\mathrm{UO}_{2}$ with nitric acid $\mathrm{HNO}_{3}$ leads to the formation of soluble salts of uranyl nitrate of formula $\mathrm{UO}_{2}\left(\mathrm{NO}_{3}\right)_{2}$. During this reaction, uranium is oxidized from the degree + IV to + VI, leading to the common designation of oxidative dissolution for this reaction. While $\mathrm{UO}_{2}$ is oxidized by nitric acid, this reaction is accompanied by the formation of nitric acid reduction by-products.

It must also be pointed out that all these studies have been realised with reaction by-products accumulation in the bulk, which must be taken into account regarding the potential autocatalytic characteristic of the dissolution of uranium dioxide in nitric acid media (the autocatalytic characteristic will be detailed later in this article).

\subsection{Proposed reaction equations}

A literature survey shows that at least eight different stoichiometric equations, summarized in $[5,6]$, are proposed to describe the balance of the reaction (Eqs. (1)-(8)).

$$
\begin{aligned}
& \mathrm{UO}_{2}+\frac{8}{3} \mathrm{HNO}_{3} \rightarrow \mathrm{UO}_{2}\left(\mathrm{NO}_{3}\right)_{2}+\frac{2}{3} \mathrm{NO}+\frac{4}{3} \mathrm{H}_{2} \mathrm{O} \\
& \mathrm{UO}_{2}+4 \mathrm{HNO}_{3} \rightarrow \mathrm{UO}_{2}\left(\mathrm{NO}_{3}\right)_{2}+2 \mathrm{NO}_{2}+2 \mathrm{H}_{2} \mathrm{O} \\
& \mathrm{UO}_{2}+\frac{5}{2} \mathrm{HNO}_{3} \rightarrow \mathrm{UO}_{2}\left(\mathrm{NO}_{3}\right)_{2}+\frac{1}{4} \mathrm{~N}_{2} \mathrm{O}+\frac{5}{4} \mathrm{H}_{2} \mathrm{O} \\
& \mathrm{UO}_{2}+\frac{12}{5} \mathrm{HNO}_{3} \rightarrow \mathrm{UO}_{2}\left(\mathrm{NO}_{3}\right)_{2}+\frac{1}{5} \mathrm{~N}_{2}+\frac{6}{5} \mathrm{H}_{2} \mathrm{O} \\
& \mathrm{UO}_{2}+\frac{9}{4} \mathrm{HNO}_{3} \rightarrow \mathrm{UO}_{2}\left(\mathrm{NO}_{3}\right)_{2}+\frac{1}{4} \mathrm{NH}_{3}+\frac{3}{4} \mathrm{H}_{2} \mathrm{O} \\
& \mathrm{UO}_{2}+3 \mathrm{HNO}_{3} \rightarrow \mathrm{UO}_{2}\left(\mathrm{NO}_{3}\right)_{2}+\frac{1}{2} \mathrm{NO}+\frac{1}{2} \mathrm{NO}_{2} \\
& +\frac{3}{2} \mathrm{H}_{2} \mathrm{O}_{2}
\end{aligned}
$$

Table 1. Methods used by Hermann [5] for dissolution off-gases analysis.

\begin{tabular}{lll}
\hline $\begin{array}{l}\text { Analyzed } \\
\text { species }\end{array}$ & Method & Result \\
\hline $\mathrm{N}_{2}$ & Gas chromatography & Not detected \\
$\mathrm{NH}_{4}^{+}$ & $\begin{array}{l}\text { Measured in the } \\
\text { dissolution solution }\end{array}$ & Not detected \\
$\mathrm{NO}$ & $\begin{array}{l}\text { Chemiluminescence } \\
\text { and IR-Spectroscopy }\end{array}$ & Detected \\
$\mathrm{NO}_{2}$ & Chemiluminescence & Detected \\
$\mathrm{N}_{2} \mathrm{O}$ & IR-Spectroscopy & Detected \\
\hline
\end{tabular}

$$
\begin{gathered}
\mathrm{UO}_{2}+\frac{1}{2} \mathrm{O}_{2}+2 \mathrm{HNO}_{3} \rightarrow \mathrm{UO}_{2}\left(\mathrm{NO}_{3}\right)_{2}+\mathrm{H}_{2} \mathrm{O} \\
\mathrm{UO}_{2}+3 \mathrm{HNO}_{3} \rightarrow \mathrm{UO}_{2}\left(\mathrm{NO}_{3}\right)_{2}+\mathrm{HNO}_{2}+\mathrm{H}_{2} \mathrm{O}
\end{gathered}
$$

Looking closer at these equations, one can make the following comments:

- equation (6) is a linear combination of equations (1) and (2),

- equations (6) and (8) are related by the equilibrium presented in equation (9) [7].

$$
2 \mathrm{HNO}_{2(\mathrm{~g})}=\mathrm{NO}_{(\mathrm{g})}+\mathrm{NO}_{2(\mathrm{~g})}+\mathrm{H}_{2} \mathrm{O} .
$$

Many studies have been realized in order to determine which of these reactions are really taking place during dissolution.

\subsection{Study of gas emitted during dissolution}

Except for equations (7) and (8), proposed equations involve the formation of gaseous species. Many studies focus on the analysis of emitted gas during dissolution of uranium dioxide in nitric acid, in order to identify the species constituting them, and to try to discriminate between some of the proposed equations.

\subsubsection{Identification of the species contained in the gas}

Herrmann [5] has analyzed the composition of cooled dissolution off-gases using various methods: these methods and associated results are reported in Table 1.

Given the sensitivity of the methods used for the detection, $\mathrm{N}_{2}$ and $\mathrm{NH}_{3}$ have not been detected. On the other hand, the presence of $\mathrm{NO}, \mathrm{NO}_{2}$, and $\mathrm{N}_{2} \mathrm{O}$ is confirmed by the author.

Glatz et al. [8] have used a similar experimental system to that of Hermann, but they endeavored minimizing the contact duration between the off-gases and the dissolution medium by depositing the uranium dioxide pellet on a glass frit. A helium flow is applied, which dilutes and removes quickly the off-gases from the dissolution medium, thus avoiding any chemical reaction between the off-gases and the medium. They have confirmed the presence of $\mathrm{NO}$ and $\mathrm{NO}_{2}$, but $\mathrm{N}_{2} \mathrm{O}$ is not detected in this study. 
Table 2. Produced $\mathrm{NO}_{x}$ quantity and $\mathrm{NO} / \mathrm{NO}_{2}$ ratio for various nitric acid concentrations.

\begin{tabular}{|c|c|c|c|c|c|c|}
\hline \multirow[t]{2}{*}{ Reference } & \multirow{2}{*}{$\begin{array}{l}\text { Pellet's } \\
\text { weight (g) }\end{array}$} & \multirow{2}{*}{$\begin{array}{l}{\left[\mathrm{HNO}_{3}\right]} \\
\left(\mathrm{mol} \mathrm{l}^{-1}\right)\end{array}$} & \multirow{2}{*}{$\begin{array}{l}\text { Temperature } \\
\left({ }^{\circ} \mathrm{C}\right)\end{array}$} & \multicolumn{3}{|c|}{ Quantity and composition of collected $\mathrm{NO}_{x}$} \\
\hline & & & & $\begin{array}{l}\text { Total quantity } \\
\left(10^{-3} \mathrm{~mol}\right)\end{array}$ & NO & $\mathrm{NO}_{2}$ \\
\hline \multirow{5}{*}[9]{} & 1.0195 & 3.4 & \multirow{5}{*}{100} & 2.673 & $86 \%$ & $14 \%$ \\
\hline & 1.005 & 4.5 & & 2.599 & $84 \%$ & $16 \%$ \\
\hline & 0.9904 & 6.7 & & 2.718 & $75 \%$ & $25 \%$ \\
\hline & 1.0057 & 8.1 & & 3.642 & $45 \%$ & $55 \%$ \\
\hline & 0.9406 & 12.5 & & 4.956 & $18 \%$ & $82 \%$ \\
\hline [8] & 1.22 & 6 & 80 & $\begin{array}{l}126 \mathrm{ml} \mathrm{g}^{-1} \text { of } \\
\text { dissolved material }\end{array}$ & $34 \%$ & $66 \%$ \\
\hline
\end{tabular}

Sakurai et al. [9] have analyzed the off-gases after trapping in a liquid-nitrogen trap. The presence of $\mathrm{NO}$ and $\mathrm{NO}_{2}$ was confirmed, but they do not detect $\mathrm{N}_{2} \mathrm{O}$ in their IR-spectra. This result is also confirmed by the study of Sakurai et al. [10] on the off-gases emitted during the dissolution of irradiated uranium dioxide pellets in nitric acid.

The off-gases analysis conducted in these three works show beyond any doubt that the off-gases emitted during dissolution of $\mathrm{UO}_{2}$ in nitric acid are a mix of $\mathrm{NO}$ and $\mathrm{NO}_{2}$. This result makes sense with that of Pogorelko and Ustinov [11], who have observed a reduction in the quantity of off-gases produced during dissolution with urea addition (urea reacts with $\mathrm{NO}_{x}$ species). Nevertheless, these studies do not agree on the presence or not of $\mathrm{N}_{2} \mathrm{O}$ in the off-gases.

Comparison of the IR-spectra to the NIST Chemistry WebBook IR-spectra of water and detected $\mathrm{NO}_{x}$ species in the dissolution off-gases shows that $\mathrm{N}_{2} \mathrm{O}$ has an absorption band at about $2300 \mathrm{~cm}^{-1}$, which is not disturbed by the presence of water nor other nitrogen oxides. It can be seen on Sakurai's spectra that this absorption band is absent. Hermann [5] and Glatz et al. [8] do not give the spectra they obtained, making the same comparison impossible. Given the strong oxidizing property of the nitric acid media in these studies, it is unlikely that $\mathrm{N}_{2} \mathrm{O}$ results of a reaction between the dissolution medium and the off-gases. Thus, the detection by Hermann [5] of $\mathrm{N}_{2} \mathrm{O}$ in the off-gases may find its origin in the difference in the experimental procedures: Herrmann sent the off-gases through a condenser before analyzing it, while Sakurai et al. [9] used a liquid-nitrogen trap to recover it before analysis. Glatz et al. [8] also placed a condenser between the IR analyser and the dissolution reactor, but the fact that the off-gases are diluted with helium before flowing through it could result in the absence of recombination reactions. Thus, it seems that $\mathrm{N}_{2} \mathrm{O}$ is not produced during dissolution of uranium dioxide in nitric acid media, and that the reason of its detection by Hermann [5] remains unclear and could be attributed to the experimental procedure she used.

It can be concluded from the review of literature that the only off-gases observed during $\mathrm{UO}_{2}$ dissolution are $\mathrm{NO}$ and $\mathrm{NO}_{2}$, thus ruling out equations (3)-(5). Nevertheless, it must be pointed out that, even in the studies which tried to
Table 3. Produced $\mathrm{NO}_{x}$ quantity and $\mathrm{NO} / \mathrm{NO}_{2}$ ratio for various nitric acid concentrations per $\mathrm{UO}_{2}$ dissolve quantity [9].

\begin{tabular}{lllll}
\hline $\begin{array}{l}\text { Pellet's } \\
\text { weight }(\mathrm{g})\end{array}$ & $\begin{array}{l}{\left[\mathrm{HNO}_{3}\right]} \\
\left(\mathrm{mol} \mathrm{l}^{-1}\right)\end{array}$ & $\mathrm{NO}_{x} / \mathrm{UO}_{2}$ & $\mathrm{NO} / \mathrm{UO}_{2}$ & $\mathrm{NO}_{2} / \mathrm{UO}_{2}$ \\
\hline 1.0195 & 3.4 & 0.71 & 0.64 & 0.07 \\
1.005 & 4.5 & 0.70 & 0.62 & 0.08 \\
0.9904 & 6.7 & 0.74 & 0.61 & 0.13 \\
1.0057 & 8.1 & 0.98 & 0.54 & 0.43 \\
0.9406 & 12.5 & 1.42 & 0.36 & 1.06 \\
\hline
\end{tabular}

minimize it, the collected off-gases have been transported through the bulk, which is a chemical reaction grey zone. It is possible that during this transport, fast chemical reaction occurs between the off-gases and the dissolution solution before analysis: it is therefore likely that the detected offgases in these studies result of the chemical equilibria between the dissolution solution and the gaseous species actually produced by the dissolution reaction. However studying these off-gases directly after their production at the solid/liquid interface is a difficult problem.

\subsubsection{Influence of nitric acid concentration on off-gases composition}

Many authors have pointed out an evolution of the $\mathrm{NO}$ $\mathrm{NO}_{2}$ ratio depending on the concentration in nitric acid of the dissolution solution $[5,8,9,12]$.

Glatz et al. [8] and Sakurai et al. [9] have measured the quantity of degased $\mathrm{NO}_{x}$ during the dissolution of $\mathrm{UO}_{2}$ pellets under various nitric acid concentrations. Table 2 presents the results they obtained, and Table 3 contains the reworked results of Sakurai et al. per $\mathrm{UO}_{2}$ dissolved quantity. Two points are emphasized by these results:

- Increasing the concentration of nitric acid or the temperature of the solution results in an increase of the quantity of $\mathrm{NO}_{x}$ produced per mole of dissolved $\mathrm{UO}_{2}$.

- The $\mathrm{NO} / \mathrm{NO}_{2}$ ratio evolves to an $\mathrm{NO}_{2}$ enrichment of the produced gas with an increase of the concentration of nitric acid. 
Table 4. List of predominance domains found in literature.

\begin{tabular}{lll}
\hline Reference & {$[12,15]$} & {$[2]$} \\
\hline Reaction 1 (Eq. (1)) & {$\left[\mathrm{HNO}_{3}\right]<10 \mathrm{moll}^{-1}$} & {$\left[\mathrm{HNO}_{3}\right]<3 \mathrm{~mol} \mathrm{l}^{-1}$} \\
Reaction 2 (Eq. (2)) & {$\left[\mathrm{HNO}_{3}\right]>10 \mathrm{~mol} \mathrm{l}^{-1}$} & {$\left[\mathrm{HNO}_{3}\right]>8 \mathrm{moll}^{-1}$} \\
\hline
\end{tabular}

It must also be pointed out that in the studies of Glatz et al. [8], two types of pellets were dissolved. Due to probable triuranium octoxide impurities remaining in one of the two pellets, the results collected in this paper only deal with the pellet sintered from pure uranium dioxide powder.

Two hypotheses exist to explain these observations.

The first one assesses a progressive change in the predominant dissolution reaction: Shabbir and Robins [12] claim that the reactions presented in equations (1) and (2) happened simultaneously. But, depending on the nitric acid concentration of the dissolution solution, one will predominate over the other. They propose the concentration of 16 molal in the bulk (about $10 \mathrm{moll}^{-1}$ ) as the concentration at which the change in predominant mechanism occurs. This concentration corresponds to the concentration at which Taylor et al. [13,14] have observed a change in the evolution of dissolution kinetics when nitric acid concentration increases, which they also attribute to a change in the dissolution mechanism.

Various domains of predominance can be found in literature, and are summarized in Table 4.

However, as mentioned earlier, it should be noticed that these concentrations refer to concentrations in the bulk, and thus do not reflect the concentrations of the solution in near contact with the solid.

The second hypothesis introduces an equilibrium between nitric acid and $\mathrm{NO}_{x}$ species: Sakurai et al. [9] claim that the only dissolution reaction taking place is represented by equation (1), and that the observed $\mathrm{NO}$ and $\mathrm{NO}_{2}$ mixture results of the equilibrium existing between these two species in nitric acid solutions.

Sicsic [7] has made a review of literature on these equilibriums, showing that two mechanisms can take place, depending on phases under consideration, and nitric acid concentration (Eqs. (10) and (11)):

- For $\left[\mathrm{HNO}_{3}\right]<6.7 \mathrm{~mol} \mathrm{l}^{-1}$ :

$$
2 \mathrm{NO}_{(\mathrm{aq})}+\mathrm{HNO}_{3(\mathrm{aq})}+\mathrm{H}_{2} \mathrm{O}_{(\mathrm{l})}=3 \mathrm{HNO}_{2(\mathrm{aq})} .
$$

- For $\left[\mathrm{HNO}_{3}\right]>13 \mathrm{moll}^{-1}$ :

$$
\mathrm{NO}_{(\mathrm{g})}+2 \mathrm{HNO}_{3(\mathrm{~g})}=3 \mathrm{NO}_{2(\mathrm{~g})}+\mathrm{H}_{2} \mathrm{O}_{(\mathrm{g})} .
$$

The equilibrium presented in equation (11) refers to the over-head gas phase and gases contained in the solution either as nucleated gases of dissolved gases, in which case the equilibrium must be modified taking into account the solubilities.

For intermediate concentrations, the two reactions would occur simultaneously, which could be represented by the sum of equations (10) and (11), as shown in equation (12).

$$
\mathrm{NO}_{(\mathrm{g})}+\mathrm{HNO}_{3(\mathrm{~g})}=\mathrm{NO}_{2(\mathrm{~g})}+\mathrm{HNO}_{2(\mathrm{~g})} .
$$

Sakurai et al. [9] do not consider that concentration and phase have an impact on the reaction equation: they only refer to equation (11). This hypothesis being supported by Lefers [16] who explains that nitrous acid is unstable, and rapidly decomposes into nitric acid solutions according to equation (13).

$$
\mathrm{HNO}_{2(\mathrm{~g})}+\mathrm{HNO}_{3(\mathrm{~g})}=2 \mathrm{NO}_{2(\mathrm{~g})}+\mathrm{H}_{2} \mathrm{O}_{(\mathrm{g})} .
$$

It must be pointed out that the stoichiometric coefficients of equations (1), (2) and (11) make any demonstration based on the analysis of produced $\mathrm{NO}$ and $\mathrm{NO}_{2}$ quantities impossible.

The existence of the equilibrium presented in equation (11) is demonstrated by Sakurai et al. [9] by the analysis of off-gases obtained by bubbling NO and $\mathrm{NO}_{2}$, diluted with nitrogen, through nitric acid solutions. The quantity and average flow rate of the bubbled gases were the same as those of the corresponding $\mathrm{UO}_{2}$ pellet dissolution (Tab. 5).

Whether the gas is $\mathrm{NO}$ or $\mathrm{NO}_{2}$, a mixture of both is obtained after bubbling through the nitric acid solution. In the case of $\mathrm{NO}$, the $\mathrm{NO} / \mathrm{NO}_{2}$ ratio always fits the one observed in the case of $\mathrm{UO}_{2}$ dissolution, whatever nitric acid concentration in the solution. Contrary to $\mathrm{NO}$, when $\mathrm{NO}_{2}$ is bubbled through the solution, the $\mathrm{NO} / \mathrm{NO}_{2}$ ratio is found to be different, from the one obtained when $\mathrm{UO}_{2}$ is dissolved, for the highest acidities. For these acidities, $\mathrm{NO}_{2}$ is present in higher proportions. Decreasing $\mathrm{NO}_{2}$ rate (and increasing the bubbling time, to keep the same quantity of $\mathrm{NO}_{2}$ bubbled) induces a lower ratio of $\mathrm{NO}_{2}$, meaning that the difference in the $\mathrm{NO} / \mathrm{NO}_{2}$ ratios is due to a too short residence time for equilibrium to establish.

It seems complicated to conclude on the sole existence of equation (1) with these results. Studies at higher acidities (in domains where Eq. (2) is supposed to predominate), would have been necessary. Nevertheless, the effect of temperature and nitric acid concentration on the $\mathrm{NO} / \mathrm{NO}_{2}$ ratio shown in Table 2 , combined to the fact that even at an acidity of $6.7 \mathrm{~mol} \mathrm{l}^{-1}$, the reaction leading to the formation of NO remains predominant, seem to indicate that NO is produced by the dissolution reaction, and seriously question the existence of a dissolution chemical reaction resulting in the formation of only $\mathrm{NO}_{2}$.

\subsubsection{Conclusion on dissolution off-gases studies}

The study of dissolution off-gases reveals that previously realized works have focused on the analysis of the off-gases flowing out of the dissolution solution. The numerous equilibria existing between these species and nitric acid make any interpretation tricky: the observed off-gases are more likely an image of the dissolution products modulated 
Table 5. Comparison between the composition of produced $\mathrm{NO}_{x}$ during $\mathrm{UO}_{2}$ pellets dissolution and by bubbling of pure $\mathrm{NO}$ and $\mathrm{NO}_{2}$ through nitric acid solutions [9].

\begin{tabular}{|c|c|c|c|c|}
\hline \multirow{2}{*}{$\begin{array}{l}\mathrm{HNO}_{3} \\
\left(\mathrm{~mol} \mathrm{l}^{-1}\right)\end{array}$} & \multirow{2}{*}{$\begin{array}{l}\text { Mass of the } \mathrm{UO}_{2} \text { pellet or } \\
\mathrm{NO}_{x} \text { content of bubbled gas }\end{array}$} & \multicolumn{3}{|c|}{ Quantity and composition of collected $\mathrm{NO}_{x}$} \\
\hline & & Total quantity (mol) & NO & $\mathrm{NO}_{2}$ \\
\hline \multirow{3}{*}{3.4} & $\mathrm{UO}_{2} 1.0195 \mathrm{~g}$ & $2.673 \times 10^{-3}$ & $86 \%$ & $14 \%$ \\
\hline & NO $25 \%$ & $2.476 \times 10^{-3}$ & $86 \%$ & $14 \%$ \\
\hline & $\mathrm{NO}_{2} 46 \%$ & $5.805 \times 10^{-3}$ & $87 \%$ & $13 \%$ \\
\hline \multirow{3}{*}{4.5} & $\mathrm{UO}_{2} 1.0050 \mathrm{~g}$ & $2.599 \times 10^{-3}$ & $84 \%$ & $16 \%$ \\
\hline & NO $25 \%$ & $2.917 \times 10^{-3}$ & $85 \%$ & $15 \%$ \\
\hline & $\mathrm{NO}_{2} 47 \%$ & $7.153 \times 10^{-3}$ & $84 \%$ & $16 \%$ \\
\hline \multirow{4}{*}{6.7} & $\mathrm{UO}_{2} 0.9904 \mathrm{~g}$ & $2.718 \times 10^{-3}$ & $75 \%$ & $25 \%$ \\
\hline & NO $25 \%$ & $2.917 \times 10^{-3}$ & $73 \%$ & $27 \%$ \\
\hline & $\mathrm{NO}_{2} 48 \%$ & $7.367 \times 10^{-3}$ & $54 \%$ & $46 \%$ \\
\hline & $\mathrm{NO}_{2} 5 \%$ & $2.420 \times 10^{-3}$ & $70 \%$ & $30 \%$ \\
\hline
\end{tabular}

by equilibria taking place between the generation of these products at the solid/liquid interface, and the analysis of the off-gases after they flowed through the solution. It would be required to study these species at a much more local scale to be able to conclude on this point. In absence of such studies, the following conclusions are made, with all the previously detailed reservations:

- The only off-gases detected during the dissolution of $\mathrm{UO}_{2}$ in nitric acid are $\mathrm{NO}$ and $\mathrm{NO}_{2}$. Equations (3)-(5) can be ruled out.

- Even if the work realized by Sakurai et al. [9] is not sufficient enough to establish beyond reasonable doubt that only $\mathrm{NO}$ is produced, the formation of $\mathrm{NO}_{2}$ by dissolution of $\mathrm{UO}_{2}$ in nitric acid is questionable, and complementary work would be required on this point.

- Equation (7) can also be ruled out: judging from the of $\mathrm{NO}_{x}$ collected, this reaction, even if it would occur, is negligible.

\subsection{Study of nitrous acid concentration during the reaction}

As shown in equation (8), another considered reaction involves the production of nitrous acid as nitric acid reduction product. This possibility has been studied by Fukasawa et al. [17]. The authors have carried out $\mathrm{UO}_{2}$ pellets dissolution using a silicon film at the solution surface. This film removes the liquid/gas interface, thus preserving nitrous acid in solution by blocking the degradation reaction occurring at this interface (Eq. (9)).

The authors have observed an increase of $\mathrm{HNO}_{2}$ concentration in the solution proportional to the increase of uranyl nitrate in the solution when the film of silicon oil is added. A titration of the solution after complete dissolution of the pellets has shown a consumption of three moles of nitric acid for one dissolved mole of $\mathrm{UO}_{2}$. The authors conclude that the occurring dissolution reaction is the one presented in equation (8).

This experiment has been reproduced by dissolving copper in nitric acid with a film of silicon oil. It appeared that an important amount of $\mathrm{NO}_{x}$ bubbles formed at the solid/liquid interface, even when a silicon oil film was added. It does not seem realistic that such a quantity of off-gases could be generated by the sole nitrous acid decomposition at the interface, judging from the lower acidity at the interface compared to that of the solution $[18,19]$, and from the low surface area of gas/liquid interfaces existing at the surface of the solid (these interfaces are required for the nitrous acid decomposition reaction to occur, equation (9)).

Thus, it seems that $\mathrm{HNO}_{2}$ is not a direct by-product of $\mathrm{UO}_{2}$ dissolution reaction. The increase in $\mathrm{HNO}_{2}$ concentration with the addition of a silicon oil film can probably be explained by the fact that this film keeps the generated $\mathrm{NO}_{x}$ in contact with the solution, increasing $\mathrm{HNO}_{2}$ concentration (see Eqs. (10)-(13)). Sicsic [7] has pointed out the existence of the equilibrium presented in equation (14) (the equilibrium constant being $4 \times 10^{2}$ at $25^{\circ} \mathrm{C}$ ). Considering equation (1) and (14), one can find one mole of $\mathrm{HNO}_{2}$ produced, and three moles of $\mathrm{HNO}_{3}$ consumed for the dissolution of one mole of $\mathrm{UO}_{2}$.

$$
2 \mathrm{NO}_{(\mathrm{aq})}+\mathrm{HNO}_{3(\mathrm{aq})}+\mathrm{H}_{2} \mathrm{O}_{(\mathrm{l})}=3 \mathrm{HNO}_{2(\mathrm{aq})} .
$$

\subsection{Oxidation mechanism of uranium dioxide by nitric acid}

Many oxidation mechanisms have been proposed in the literature. Fournier [6] has made a synthesis of these mechanisms, which can be sorted in two categories:

- mechanisms where uranium dioxide is solubilized before being oxidized,

- mechanisms where uranium dioxide is oxidized in the solid, and then moved into the solution.

The hypothesis of an oxidation after solubilization has been supported by Shabbir and Robins $[12,20]$. The mechanism involves a first step where $\mathrm{UO}_{2}$ is turned into $\mathrm{U}^{4+}$.

On the other hand, Hermann [5] has led analysis showing the absence of formation of $\mathrm{U}^{4+}$ during dissolution of $\mathrm{UO}_{2}$. Another work by Ikeda et al. [21], 
which consisted in dissolving isotopically pure $\mathrm{U}^{17} \mathrm{O}_{2}$, followed by ${ }^{17} \mathrm{O}$ NMR analysis of the solution, has shown that $\mathrm{U}-\mathrm{O}$ bonds do not break during dissolution. It is demonstrated by these two studies that the oxidation of $\mathrm{UO}_{2}$ happens most probably before any solubilization as $\mathrm{U}^{4+}$ ion.

The exact oxidation mechanism remains poorly understood: is it a two-electrons transfer mechanism, or is there formation of $\mathrm{U}(+\mathrm{V})$ as an intermediate, the mechanism being in this case a single-electron transfer?

Berger [22] proposes a single-electron transfer mechanism, as shown in equations (15) and (16):

$$
\begin{aligned}
& \mathrm{UO}_{2(\mathrm{~s})}=\mathrm{UO}_{2(\mathrm{~s})}^{+}+\mathrm{e}^{-}, \\
& \mathrm{UO}_{2(\mathrm{aq})}^{+}=\mathrm{UO}_{2}^{2+}+\mathrm{e}^{-} .
\end{aligned}
$$

Ikeda et al. [21] do not decide between the two possible ways of electron transfer, and propose one mechanism for both cases. Equation (17) presents the proposed mechanism for a two-electron transfer mechanism, which is presented as the most likely.

$$
\mathrm{UO}_{2}+2 \mathrm{NO}_{3}^{-}+4 \mathrm{H}^{+} \rightarrow \mathrm{UO}_{2}^{2+}+2 \mathrm{NO}_{2}+2 \mathrm{H}_{2} \mathrm{O} .
$$

In the event that the $\mathrm{UO}_{2}^{+}$oxidation reaction rates to $\mathrm{UO}_{2}^{2+}$ are much faster than that of the disproportionation reaction of $\mathrm{UO}_{2}^{+}$and the rate of oxygen exchange between $\mathrm{UO}_{2}^{+}$and water is slow, the authors also consider a singleelectron transfer mechanism presented in equations (18) and (19).

$$
\begin{gathered}
\mathrm{UO}_{2}+\mathrm{NO}_{3}^{-}+2 \mathrm{H}^{+} \rightarrow \mathrm{UO}_{2}^{+}+\mathrm{NO}_{2(\mathrm{aq})}+\mathrm{H}_{2} \mathrm{O}, \\
\mathrm{UO}_{2}^{+}+\mathrm{NO}_{3}^{-}+2 \mathrm{H}^{+} \rightarrow \mathrm{UO}_{2}^{2+}+\mathrm{NO}_{2(\mathrm{aq})}+\mathrm{H}_{2} \mathrm{O} .
\end{gathered}
$$

Nevertheless, the lack of data concerning the different rates mentioned earlier makes this last mechanism hypothetical.

\subsection{Conclusion on the reaction of uranium dioxide with nitric acid}

This first part has focused on the studies realized to understand the chemical reaction of uranium dioxide with nitric acid. These studies have demonstrated that only two off-gases are produced during dissolution: nitrogen monoxide $\mathrm{NO}$ and dioxide $\mathrm{NO}_{2}$.

A doubt remains on the origin of these two gases: are they both produced by the dissolution reaction, or is nitrogen dioxide a result of equilibria existing between nitric acid and nitrogen monoxide? In any case, even if the study of Sakurai et al. [9] is not sufficient to decide clearly on this point, it shows that if both off-gases are considered to be produced by the dissolution reaction, the predominance domain of equation (10) should be revised, and is likely to be more extended than expected. Thus, the main reaction occurring would be represented by the massbalance equation presented in equation (1).
The oxidation mechanism of uranium dioxide, which turns $\mathrm{U}(+\mathrm{IV})$ into $\mathrm{U}(+\mathrm{VI})$, does not involve the $\mathrm{U}=\mathrm{O}$ bonds rupture, and likely happens in the solid phase. For now, it is not possible to decide between one or two electron transfer mechanisms.

\section{Solid side of the dissolution reaction}

\subsection{Overview of solid properties}

Uranium dioxide dense pellets are commonly obtained by sintering at high temperature (1973-2023 K) under reductive atmosphere (dry $\mathrm{Ar} / \mathrm{H}_{2} 5 \%$ ) of raw pellets mainly composed of overstoichiometric $\mathrm{UO}_{2+\delta}$ and few weight percent of $\mathrm{U}_{3} \mathrm{O}_{8}$. In this case, $\mathrm{U}_{3} \mathrm{O}_{8}$ is used as an inorganic (i.e. radiolysis-proof) performer. During the sintering thermal treatment between $773 \mathrm{~K}$ and $873 \mathrm{~K}[23,24]$, this oxide is reduced to $\mathrm{UO}_{2}$. Since the theoretical density of $\mathrm{UO}_{2}$ is 10.97 and that of $\mathrm{U}_{3} \mathrm{O}_{8} 8.38$ [25], a volume contraction of around $24 \%$ of the initial $\mathrm{U}_{3} \mathrm{O}_{8}$ grains occurs, generating an additional porosity. The latter yields to pellet final densities of around 95\% TD (theoretical density), which allows fuel mechanical accommodations during irradiation.

After sintering, monophasic and stoichiometric $\mathrm{UO}_{2.00}$ is formed presenting a cubic fluorite-like structure with space group Fm-3m (No. 225). The use of $\mathrm{UO}_{2}$ and $\mathrm{U}_{3} \mathrm{O}_{8}$ grades ensures that neither additional phases nor significant quantities of impurities are present. Pellets have homogeneous microstructure generally composed of large grains $(\sim 10 \mu \mathrm{m})$ associated by grain boundaries. A grain is considered as a crystallite with only one single crystallographic orientation whereas the grain boundary ensures the transition between two grains presenting different crystallographic orientations. As a consequence, grains boundaries generally have lower crystallographic orders and due to/because of their thickness (few nanometers) can be considered as two-dimension defects. The residual porosity is not preferentially located in the bulk or in the grain boundaries and is mainly closed.

Greiling and Lieser [26] have noted that manufacturing conditions of the powders they used for their dissolution experiments have an impact on dissolution kinetics.

In the case of sintered solids, manufacturing conditions will have an impact on solid's consolidation and density, these two parameters having in turn an impact on pellets' dissolution kinetics, as shown by Taylor et al. [13] and Uriarte and Rainey [27].

\subsection{Preferential attack sites}

Studies realized by Briggs $[28,29]$ and Shabbir and Robbins [30] have revealed that dissolution kinetics vary with crystallographic orientation of the surface exposed to the solution: grains with crystallographic orientation (111) parallel to the surface show slower dissolution kinetics than those with crystallographic orientation (1 00 ) parallel to the surface. This seems to be in agreement with the results of Castell et al. [31] and Muggelberg et al. [32,33] who have studied the $\left(\begin{array}{lll}1 & 0 & 0\end{array}\right),\left(\begin{array}{lll}1 & 1 & 0\end{array}\right)$ and $\left(\begin{array}{lll}1 & 1 & 1\end{array}\right)$ surface of uranium dio-

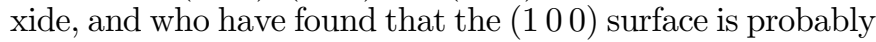
less stable than the other ones due to a higher surface energy. 


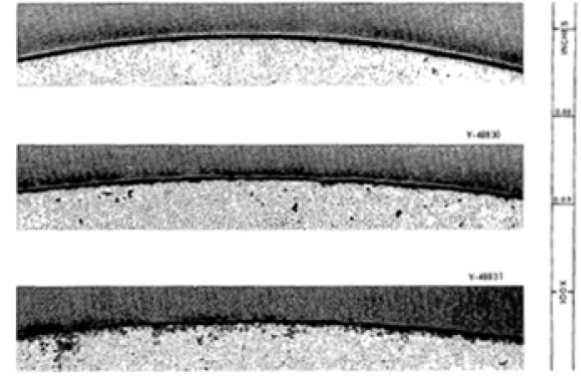

(a)

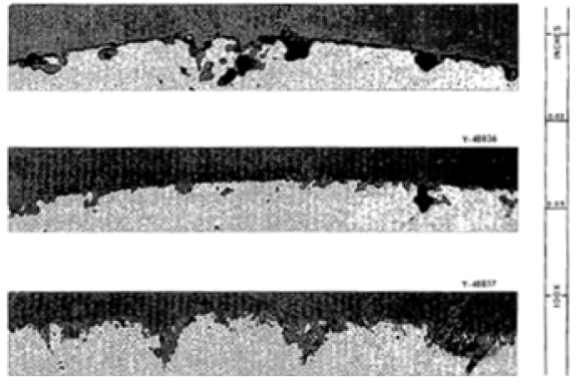

(b)

Fig. 1. Metallographic sections of $\mathrm{UO}_{2}$ pellets before (a) and after (b) dissolution [27].

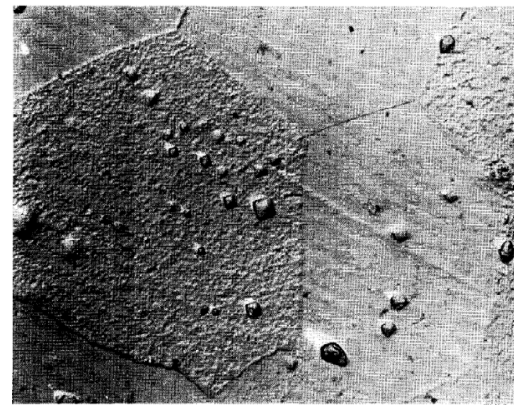

(a)

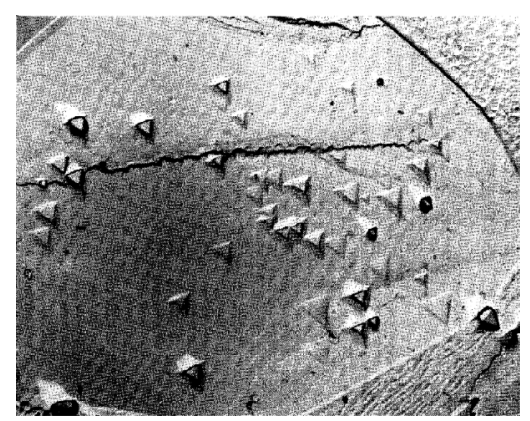

(b)

Fig. 2. Electron micrograph of polycrystalline $\mathrm{UO}_{2}$ attacked by 37 molal nitric acid [30].

These works, as well as those of Uriarte and Rainey [27], Kim et al. [34] and Zhao and Chen [35-37], let also appear preferential attack sites:

- Grain boundaries, which can be explained by the fact that these areas are poorly crystallized, with lower cohesion energy (Fig. 1). This probably makes these areas more apt for dissolution.

- Other very located sites on the surface of the grains

(Fig. 2). The origin of these pits remains unknown.

The attack and development of the surface and number of these sites lead to an increase of the specific surface area and thus probably, but not necessarily, of the reactive surface of the solids in the first part of dissolution, as measured by Taylor et al. [13,14], Fukasawa and Ozawa [38], and Fournier [6]. It is observed that the specific surface area can grow up to a factor of 4 , and that the maximum development is measured when $20-40 \%$ of the solid is dissolved. After this first period, the specific surface area decreases to zero due to the consumption of the solid.

However, the issue of internal mass transport makes the relation between reactive surface and specific surface area complicated to establish $[39,40]$, and no study has yet demonstrated a convincing relationship between reactive surface and specific surface area.

\section{An autocatalyzed reaction?}

A particularity of the dissolution reaction of $\mathrm{UO}_{2}$ in nitric acid media is the supposed existence of an autocatalytic reaction, which means that one of the products of the dissolution reaction would act as a catalyst. This assessment is nowadays commonly accepted, even though neither the species involved nor the mechanisms have been formally identified.

\subsection{Observations in favor of the existence of an autocatalytic reaction}

Many experimental observations reported in the literature support the assessment of an autocatalytic mechanism.

Wada et al. [41] have studied the effect of UV irradiation on the dissolution of uranium dioxide powders in nitric acid solutions. In their blank tests (without UV irradiation), and all else being equal, the measured dissolution rates are multiplied by almost ten when the amount of uranium dioxide powder dissolved increased from 10 to $100 \mathrm{mg}$.

\subsubsection{Effect of mixing}

Shabbir and Robins [12,20], Taylor et al. [13,14], Delwaulle [19] and Zhao and Chen [35-37] have reported that increasing mixing for batch dissolution, or input flow for continuous dissolution, results in a decrease in dissolution kinetics (Fig. 3).

This effect is against what one would intuitively expect, i.e. that increasing mixing or input flow results in lowering the thickness of the diffusion layer, increasing reactants' mass transport and dissolution kinetics. But, if there were an autocatalytic reaction, increasing mass transport would also result in lowering the concentration of products at the solid/liquid interface, including potential catalytic species. 


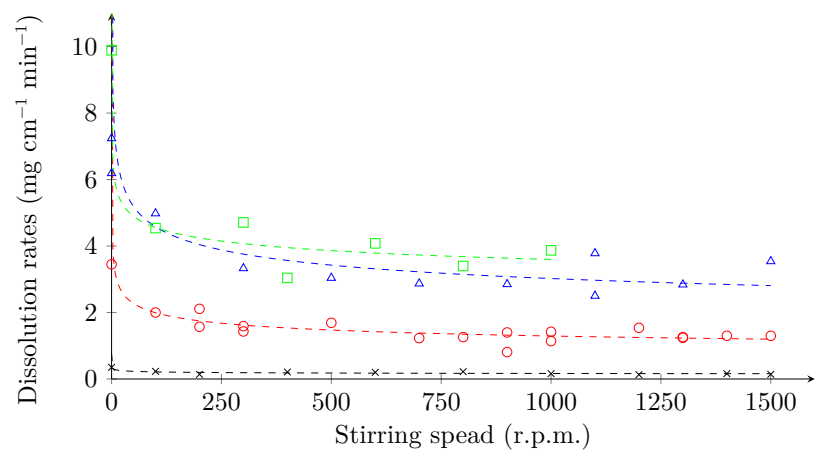

$-\star-50{ }^{\circ} \mathrm{C}-\ominus-80{ }^{\circ} \mathrm{C}-\triangle-95{ }^{\circ} \mathrm{C}-\boxminus-80{ }^{\circ} \mathrm{C}-\left[\mathrm{UO}_{2}\left(\mathrm{NO}_{3}\right)_{2}\right]=2 \mathrm{~mol} \mathrm{l}{ }^{-1}$

Fig. 3. Effect of stirring speed on the dissolution rates of uranium dioxide pellets in $\left[\mathrm{HNO}_{3}\right]=6 \mathrm{~mol} \mathrm{l}^{-1}[13]$.

The only paper reporting a positive impact of mixing is the one of Kumar Gelatar et al. [42], who report that the dissolution kinetics of uranium dioxide are faster under continuous recirculation of the dissolution solution. This observation can probably be explained by the fact that in this particular case, the mixing involved by the recirculation is probably weak, and simply re-introduces catalytic species into the dissolver.

\subsubsection{Induction period}

At the beginning of dissolution, there is a period of time where observed dissolution kinetics are lower than those expected for a homogeneous attack of the solid. In the hypothesis of an autocatalytic mechanism, this period would correspond to the time required to reach the autocatalytic species' equilibrium concentration, at the solid/liquid interface.

It must be pointed out that this period could also correspond to an increase of the reactive surface area of the solid, but this explanation cannot support the negative effect of mixing on dissolution kinetics. Most probably, combinations of both effects occur.

\subsection{Potential autocatalytic species}

\subsubsection{Nitrous acid}

Nitrous acid is the historically supposed autocatalytic species. As early as 1962, Taylor et al. [13,14] presented nitrous acid as a catalyst of $\mathrm{UO}_{2}$ dissolution reaction. This observation is related to the increase of dissolution kinetics they observed when adding nitrite salts to solution or $\mathrm{Fe}\left(\mathrm{NO}_{3}\right)_{3}$ reducing to $\mathrm{Fe}(\mathrm{II})$ in the solution, which reacts in its turn with nitric acid leading to nitrous acid. Myasoedov and Kulyako [43] have also carried out experiments with addition of iron(III) nitrate, but they did not study the effect of this salt on the dissolution kinetics of uranium dioxide. Taylor et al. [13,14] and Pogorelko and Ustinov [11] have also reported a decrease of the dissolution kinetics when urea or hydrazine (which act as nitrous scavengers) are added to the solution.
Similar observations are reported by Shabbir and Robins [20], Herrman [5], Pogorelko and Ustinov [11], Nishimura et al. [44], Yasuike et al. [45], Ikeda et al. [32] and Carrott et al. [46].

Nishimura et al. [44] and Kim et al. [34,47] have proposed the mechanism presented in equation (20) to explain the role of nitrous acid. This mechanism was reused by Homma et al. [48], who have claimed that nitrous acid would be produced by the reaction between nitrogen dioxide and water (Eq. (21)). Inoue [49,50] also supports the mechanism presented in equation (20).

$$
\begin{gathered}
\mathrm{UO}_{2}+2 \mathrm{HNO}_{2}+2 \mathrm{H}^{+} \rightarrow \mathrm{UO}_{2}^{2+}+2 \mathrm{NO}+2 \mathrm{H}_{2} \mathrm{O}, \\
2 \mathrm{NO}_{2(\mathrm{aq})}+\mathrm{H}_{2} \mathrm{O} \rightarrow \mathrm{HNO}_{3}+\mathrm{HNO}_{2} .
\end{gathered}
$$

It must be pointed out that in the case of a catalyzed reaction, the catalytic species must be returned at the end of the reaction. The "autocatalytic" term used to describe the assessed mechanism is thereof incorrect: nitrous acid should be returned at the end of the reaction, which is not the case in the proposed mechanism.

\subsubsection{Uranyl nitrate}

Herrmann [5], Taylor et al. [13,14], Uriarte and Rainey [27], and Homma et al. [48] have done dissolution experiments with uranyl nitrate addition. The authors observed that in the case where uranyl nitrate is added keeping total nitrate concentration constant (which means decreasing nitric acid concentration depending on the quantity of uranyl nitrate added), no impact is observable on dissolution kinetics. On the other hand, if uranyl nitrate is added, and total nitrate concentration increased, there is an acceleration of dissolution kinetics. This last point must be related to the fact that about $80-90 \%$ of nitric acid can be replaced by monovalent salts of nitrate with hardly an impact on dissolution kinetics, as reported by Taylor et al. [13] and Uriarte and Rainey [27].

Thus, uranyl nitrate does not seem to be the autocatalytic species.

\subsubsection{Other considered species}

Nitrous acid is a weaker acid and weaker oxidizer than nitric acid. But, its instability in nitric acid solutions makes it in equilibrium with much more reactive species. At least two of these species are found in the literature as potential autocatalytic species

- Nitroacidium ion $\left(\mathrm{H}_{2} \mathrm{NO}_{2}^{+}\right)[50]$ :

$$
\mathrm{UO}_{2}+\mathrm{H}_{2} \mathrm{NO}_{2}^{+} \rightarrow \mathrm{UO}_{2}^{+}+\mathrm{NO}+\mathrm{H}_{2} \mathrm{O}
$$

- Nitrosonium ion $\left(\mathrm{NO}^{+}\right)$[5]:

$$
\mathrm{UO}_{2}+\mathrm{NO}^{+} \rightarrow \mathrm{UO}_{2}^{+}+\mathrm{NO} .
$$

The reactivity of these species makes their identification in the solution tricky, and the possibility that they have a role in dissolution reaction remains yet hypothetic. 


\subsection{Elements against the existence of an autocatalyzed reaction}

Two experimental facts disagree with the hypothesis of an autocatalyzed reaction.

\subsubsection{The replacement of nitric acid by nitrate salts}

As reported earlier in this paper, Taylor et al. [13] and Uriarte and Rainey [27] have undertaken dissolution experiments of $\mathrm{UO}_{2}$ pellets where part of the nitric acid was replaced by nitrate salts keeping total nitrate concentration constant. It has been observed that about $80-90 \%$ of nitric acid could be replaced by an equivalent quantity of monovalent nitrate without impacting dissolution kinetics.

This observation disagrees with the hypothesis of an autocatalyzed reaction, since by modifying the concentration of nitric acid, one also modified the concentration of all the species at equilibrium with it. This means that any by-product of the reduction of nitric acid will see its concentration changed, and if one of them were catalyzing the reaction, a change in its concentration should impact the overall dissolution kinetics, except if the equilibria between the different species are thresholded.

\subsubsection{The increase of nitrous acid concentration}

Contrary to what has been presented earlier, some authors did not report any impact of nitrous acid or nitrite salts on dissolution kinetics.

Uriarte and Rainey [27] have added sodium nitrite without significant increase in dissolution kinetics. Nevertheless, the authors precise that this addition was made in boiling dissolution solutions, and that the high temperature could accelerate the degradation of the added nitrites. It must also be noted that higher temperatures affect the solubilities of the off-gases produced when nitrites degrade, and that water vapor entrainment could also further lower the off-gases concentrations in solution. These two phenomena could shift the chemical equilbria in favor of nitrites degradation.

Fukasawa et al. [17], in their work with silicon oil films, have noted that the addition of this film resulted in a conservation of nitrous forms in solution. They did not observe any change in dissolution kinetics by increasing by this way the concentration of nitrous acid.

\section{Physico-chemical parameters influencing the dissolution rates}

This part presents a compilation of the main physicochemical parameters known for having an impact on the dissolution rates. Nevertheless, it must be pointed out that the results have been obtained using a broad variety of materials (sintering conditions, physical form such as powders, spheres, or pellets), and of dissolution solutions compositions.
This point is although fundamental, for example if one wants to draw conclusions on the chemical mechanisms based on the measurement of dissolution rates. These uncertainties make the conclusions learned from the kinetics measurements uncertain, and are probably responsible for the variety of the results found in the literature, presented below.

\subsection{Nitric acid concentration}

The impact of nitric acid concentration in the attacking solution has been widely studied in the literature, and conclusions are unanimous: increasing this concentration increases dissolution kinetics.

Taylor et al. [13,14] have reported the increase of dissolution kinetics with nitric acid in the case of unstirred dissolutions. This increase remains constant up to a value, depending on the temperature of the solution, beyond which the increase slows down. Shabbir and Robins [12] have found the same results, and attribute the inflexion of the kinetics increase to a change in the nitric acid reduction mechanism.

Similar results have also been reported by Uriarte and Rayney [27] when dissolving uranium dioxide pellets in boiling nitric acid, and by Hermann [5] and Calaparede et al. [51] but within a smaller range of nitric acid concentrations.

Many authors have taken into account this impact of nitric acid concentration by the mean of equation (24). Table 6 presents a compilation of the different values which have been reported for the partial order of nitric acid $n$.

$$
r=k \times\left[\mathrm{HNO}_{3}\right]^{n} .
$$

\subsection{Temperature of the solution}

The impact of temperature on the dissolution kinetic has also been widely studied. The assessments are unanimous on its effects $[5,13,14]$, and can be summarized as follow:

- the increase of the temperature results in an increase of the dissolution kinetics up to temperatures around 90- $95^{\circ} \mathrm{C}$,

- from 90 to $95^{\circ} \mathrm{C}$ to boiling, kinetics keep increasing, but slower than for lower temperatures,

- the reaching of boiling makes kinetics drop. The authors have explained this drop by the solution mixing that boiling involves, but it could also be explained by the effect of temperature on nitrites degradation, gas solubilities and water vapor entrainment, detailed in Section 4.3.2.

Considering that the kinetic constant follows the Arrhenius law (Eq. (25)), Table 7 gives the values of the activation energy reported in the literature.

$$
k=A \exp \left(\frac{-E_{a}}{R T}\right) .
$$

The fact that calculated activation energy is not constant over the temperature domain indicates that the dissolution of uranium dioxide is not following the 
Table 6. Partial order related to nitric acid in the case of equation (25).

\begin{tabular}{lllll}
\hline Reference & \multicolumn{3}{c}{ Experimental conditions } & $n$ \\
\cline { 2 - 5 } & {$[\mathrm{U}]\left(\mathrm{g} \mathrm{l}^{-1}\right)$} & {$\left[\mathrm{HNO}_{3}\right](\mathrm{N})$} & Temperature $\left({ }^{\circ} \mathrm{C}\right)$ & $2.3-3.3$ \\
\hline 14$]$ & - & $2-10$ & $20-95$ & 1 \\
& & $10-14$ & Boiling & $2.03-2.12$ \\
{$[27]$} & $120-350$ & $2-7$ & Boiling & 2.3 \\
{$[45]$} & - & $2-12$ & 80 & 2.3 \\
\hline
\end{tabular}

Table 7. Activation energy values reported by authors.

\begin{tabular}{|c|c|c|c|}
\hline \multirow{2}{*}{ Reference } & \multicolumn{2}{|c|}{ Experimental conditions } & \multirow[t]{2}{*}{$E_{a}\left(\mathrm{~kJ} \mathrm{~mol}^{-1}\right)$} \\
\hline & {$\left[\mathrm{HNO}_{3}\right]\left(\mathrm{mol} \mathrm{l}^{-1}\right)$} & Temperature $\left({ }^{\circ} \mathrm{C}\right)$ & \\
\hline [5] & $4.5-8$ & $60-95$ & 50 \\
\hline [8] & 6 & $50-95$ & 54.8 \\
\hline & $2-10$ & $20-95$ & $61.9 \pm 5.5$ \\
\hline [14] & 14 & $65-95$ & $8.3-21$ \\
\hline [30] & \multicolumn{2}{|c|}{ Wide area with chemical control } & 67 \\
\hline [35] & 8 & 90 & 50 \\
\hline \multirow{3}{*}[36]{} & \multirow[b]{2}{*}{8} & $\begin{array}{l}\text { 90-110 } \\
\text { (Micro-wave heating) }\end{array}$ & 71 \\
\hline & & $\begin{array}{l}90-110 \\
\text { (Classical heating) }\end{array}$ & 50 \\
\hline & \multirow{2}{*}{4} & $\begin{array}{l}90-110 \\
\text { (Micro-wave heating) }\end{array}$ & 77.4 \\
\hline$[37]$ & & $\begin{array}{l}90-110 \\
\text { (Classical heating) }\end{array}$ & 31.1 \\
\hline [51] & 2 & $40-90$ & $15 \pm 1$ \\
\hline & 8.05 & $70-90$ & 85.2 \\
\hline [52] & 10.28 & $60-80$ & 97.5 \\
\hline
\end{tabular}

Arrhenius law. This could be due to a change in the chemical reaction mechanism with temperature, a change in the mechanism controlling the overall kinetics, or other physico-chemical effects like those induced by boiling on the gas solubilities, or mass-transport phenomena.

\subsection{Solid properties}

\subsubsection{Density and specific surface area of the solid}

As shown earlier, the attack of the solid is not uniformous. This results in an increase of the solid specific surface area during the earliest stages of dissolution.

This increase has been measured by Taylor et al. [13,14] (Fig. 4), and by Fukasawa and Ozawa [38]. The authors report that the specific surface area can increase by a factor of 4 during dissolution, this maximum being reached when $20-40 \%$ of the solid is dissolved.

The density of the solid, which also impacts its specific surface area, has also been studied by Taylor et al. [13] and by Uriarte and Rainey [27]. Despite important disparities in their results, the authors have reported that the decrease of the density of the solid results in an increase of the dissolution rates. However, it is important to notice once again that no relation between specific surface area and reactive surface has been demonstrated yet.

\subsubsection{Role of impurities}

The role of some impurities has been studied by Ikeda et al. [53]. The authors have found that the dissolution rates of uranium dioxide powders containing impurities $\left(\mathrm{Al}_{2} \mathrm{O}_{3}\right.$, $\mathrm{Pd}, \mathrm{Rh}, \mathrm{Ru}$ or $\mathrm{ZrO}_{2}$ ) are significantly faster compared to the dissolution rate of pure uranium dioxide based powders. They have attributed these accelerations to the lower density of the uranium dioxide solids containing $\mathrm{Al}_{2} \mathrm{O}_{3}$ and $\mathrm{ZrO}_{2}$ as compared to the density of the pure uranium dioxide solids, without arguing how. The fact that the dissolution rate of the solids containing rhodium is faster than those of the solids incorporating $\mathrm{Al}_{2} \mathrm{O}_{3}$ and $\mathrm{ZrO}_{2}$, while all these solids show the same density, indicates that another mechanism, which remains unknown, takes place in this case. 


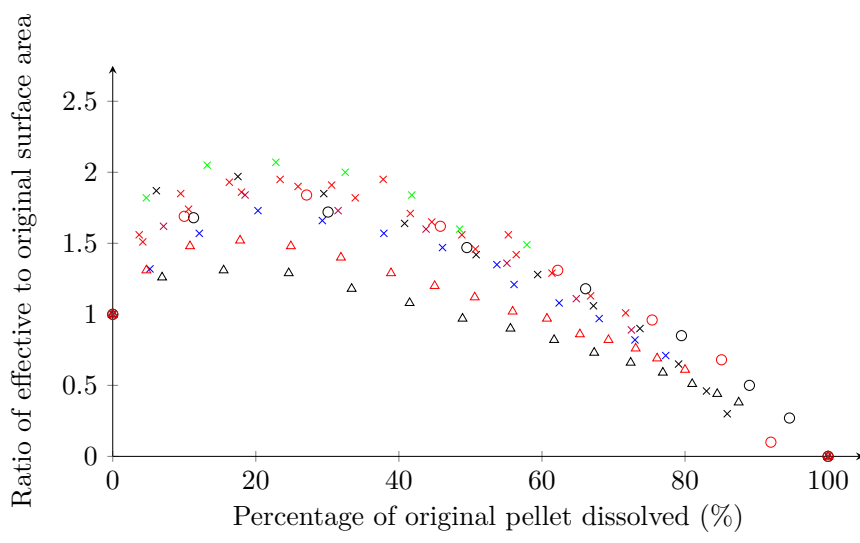

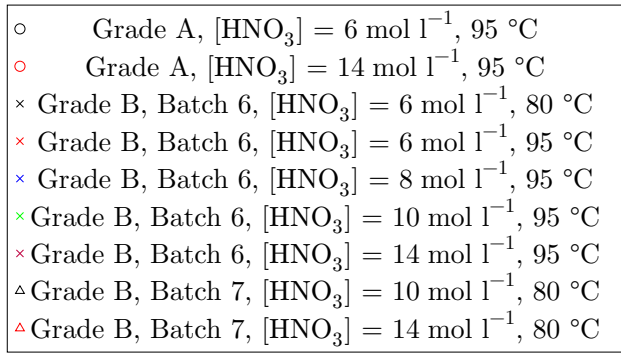

Fig. 4. Evolution of the effective surface area of dissolving pellets under various conditions as a function of the percentage of original pellet dissolved [13].

They have also reported a difference between the densities of the different materials, impure uranium dioxide powders being found to be less dense than pure uranium dioxide ones (93\% TD as compare to $95 \%$ TD). However, the authors claim that the difference of densities is too small to explain the differences observed for the dissolution rates.

In addition, Tocino et al. [54] have realised dissolution of uranium dioxide pellets containing significant quantities (25\%) of lanthanides and actinides (Ce, Gd, Nd, Th), and reported slower dissolution rates than in the case of pure uranium dioxide dissolution. This could indicate that these elements can also have an impact at lower contents.

\subsection{Conclusion on the influence of the physico- chemical parameters on the dissolution rates}

Despite important variabilities in the results, it can be concluded that the increase of nitric acid concentration and temperature of the dissolution solution results in an increase of the dissolution rates, except when temperature reaches the boiling point: in this case, the dissolution rates brutally drops. In addition, it must be noticed that the effect of the temperature does not fit the Arrhenius law. This could be due to a change in the chemical reaction mechanism, or in other physico-chemical phenomena, and further investigations would be required to conclude clearly on this point.

The characteristics of the solid also play an important role on the dissolution rates, and a relation, which needs to be clarified, exists between the specific surface area of the dissolving solids, probably also impacted by the density of the solid, and the dissolution rates.
Another important point is the fact that most of the studies have not taken interest in the rate controlling mechanism. The primary importance of the knowledge of this mechanism has been widely documented in the literature concerning the kinetics of solid/liquid reactions $[39,40,55]$, and its absence in most of the studies results in the impossibility to know if the measured dissolution rates correspond to the chemical reaction or diffusion kinetics.

Some authors have specified the rate-determining step in their experiment, but their conclusions, even for similar experimental conditions, do not agree. Claparede et al. [51], Desigan et al. [52] and Tocino et al. [54] have found that the activation energy values they have calculated do not correspond to the expected values for a diffusion-controlled processes, and have concluded that the dissolution reaction is likely to take place under chemical control. Nevertheless, this conclusion relies on a serial transport, diffusion and reaction mechanism, which could not take place during uranium dioxide dissolution. Additionally, these conclusions are not in agreement with the observations made by Delwaulle et al. [18,19], who have observed nitric acid concentrations gradients surrounding sintered fragments of uranium dioxide during their dissolution.

The impact of other physico-chemical parameters has been partially studied in the literature, such as the effect of pressure and atmosphere composition by Shabbir and Robins [20]. However, the small number of studies dedicated to the impact of these other parameters makes any discussion on the conclusions they draw too complicated.

Finally, it appears that the knowledge of the rate determining step in these experiments, including the diffusion of the chemical species in the external diffusion layer, is a key element which is most of the time absent, or insufficiently investigated, to draw well-established conclusions.

\section{Conclusion}

This work has made a state of the art concerning uranium dioxide dissolution in nitric acid solutions. The first conclusion which can be drawn is that this reaction is a complex reactive dissolution reaction, which involves solid, liquid and gazeous species, and a possible autocatalytic reaction. This is complicated by the fact that all these species, and their associated parameters, evolve during the dissolution, and vary from one study to another.

The studies found in the literature have mainly focused on two aspects of this reaction: the understanding of the chemical reaction between uranium dioxide and nitric acid, and the determination of the influence of several physicochemical parameters of the reaction on the dissolution rates.

Concerning the chemical reaction, it can be seen from the literature that the reaction leads to the production of nitrogen monoxide $\mathrm{NO}$ and dioxide $\mathrm{NO}_{2}$ as by-products, thus making equations (1) and (2) the most likely equations for the mass-balance of the reaction. 
The fact that the $\mathrm{NO} / \mathrm{NO}_{2}$ ratio evolves with nitric acid concentration has led to the development of two hypotheses, which are still being debated:

- both reactions take place, but the ratio of one over the other varies with nitric acid concentration,

- equation (1) is the only reaction occurring during dissolution, and the formation of $\mathrm{NO}_{2}$ is a result of the equilibria between $\mathrm{NO}$ and $\mathrm{HNO}_{3}$ in the solution including their solubilities.

Concerning the mechanism of the oxidation of uranium dioxide, it has been clearly demonstrated that solubilization occurs after oxidation. The electron exchange has not been elucidated yet, and the question of single-electron transfer and two-electrons transfer mechanisms is still open.

Another important aspect of this reaction deals with the solid phase. Dissolution does not occur as a uniformous attack, and this leads to important changes in the morphology of the solid, with the appearance of pits and the development of cracks, which imply an increase in the surface of the solid.

The last point concerning the chemical reaction is its supposed autocatalytic property. It has been emphasized that even if this hypothesis is historically and widely accepted in the literature, many elements remain missing on this point: what is exactly the autocatalytic mechanism? Which are the species involved in this mechanism? More work would be required on this subject to clearly elucidate the mechanism of the possible autocatalysis of uranium dioxide dissolution in nitric acid solutions. But the complexity of nitric acid media, which contain many different species related together by multiple equilibria, makes experimental results tricky to analyze, and most of the time, conclusions must be carefully drawn.

The study of the impact of several physico-chemical parameters of the reaction is presented in the second part of this review. Even if the rate determining step of these experiments is not sufficiently known, some conclusions can be drawn based on these results.

The increase of nitric acid concentration and temperature of the dissolution solution results in an increase of the dissolution rates, except near the boiling point, where the dissolution rates brutally drops. This observation is probably due to the increase of the mixing due to the bubbling taking place once the boiling point of the solution is approached. It must also be noticed that the dissolution rates do not follow the Arrhenius law. This could be due to a change in the chemical reaction mechanism, in the rate determining step, or the effect of the temperature on the solubilities of the gas and water vapor entrainment of the dissolved gases.

The characteristics of the solid also play an important role on the dissolution rates. It is commonly accepted that higher specific surface area induces higher dissolution rates, although no formal relation between the reactive surface and the specific surface area of the solid, including the issue of mass-transport, has been demonstrated yet.
To conclude, the compilation of the studies found in the literature has allowed to clarify several points on the dissolution of uranium dioxide in nitric acid media. Nevertheless, this review also enlights numerous lacks of understanding concerning this reaction. It appears that these can mainly be assigned to the fact that most of the studies have been realised at a macroscopic scale, which is not adaptated to the phenomenological complexity and speed of this reaction. Thus, new approaches, enabling to better quantify the contribution of the different phenomena, would be required to better understand the mechanisms of this reaction. This better knowledge of the reaction would enable in turn to improve the dissolution step of the processes used for spent nuclear fuels recycling, but also for other dissolution reactions that imply reaction off-gas and catalysis.

This work was financed by the French Alternative Energies and Atomic Energy Commission and AREVA NC.

\section{References}

1. C. Poinssot, S. Bourg, N. Ouvrier, N. Combernoux, C. Rostaing, M. Vargas-Gonzalez, J. Bruno, Energy 69, 199 (2014)

2. M. Bourgeois, Retraitement du combustible: Principales opérations (Techniques de l'ingénieur, 2000)

3. B. Boullis, Treatment and recycling of spent nuclear fuels, in DEN Monographs (Éditions du Moniteur, Paris, 2008), p. 7

4. C. Poinssot, C. Rostaing, S. Grandjean, B. Boullis, Proc. Chem. 7, 349 (2012)

5. B. Hermann, Dissolution of unirradiated $\mathrm{UO}_{2}$-pellets in nitric acid. Technical document Ref. 3673 (Karlsruher Institut für Technologie, 1984)

6. S. Fournier, Étude de la dissolution des oxydes mixtes (U,Pu) $\mathrm{O}_{2}$ à forte teneur en plutonium, $\mathrm{PhD}$ thesis, Université de Montpellier, 2000

7. D. Sicsic, Modélisation thermodynamique et cinétique de la réduction de l'acide nitrique concentré, $\mathrm{PhD}$ thesis, Université Pierre et Marie Curie, 2011

8. J.-P. Glatz, H. Bokelund, S. Zierfuß, Radiochim. Acta 51, 17 (1990)

9. T. Sakurai, A. Takahashi, N. Ishikawa, Y. Komaki, Nucl. Technol. 83, 24 (1988)

10. T. Sakurai, A. Takahashi, N. Ishikawa, Y. Komaki, M. Ohnuki, T. Adachi, J. Nucl. Sci. Technol. (Abingdon, U.K.) 30, 533 (1993)

11. O.N. Pogorelko, O.A. Ustinov, Radiochemistry 35, 182 (1993)

12. M. Shabbir, R.G. Robins, J. Appl. Chem. 18, 129 (1968)

13. R.F. Taylor, E.W. Sharratt, L.E.M. de Chazal, D.H. Logsdail, Processing in limited geometry. Part III. The dissolution of uranium dioxide sintered pellets in nitric acid. Technical document Ref. AERE-R 3678 (United Kingdom Atomic Energy Authority, 1962)

14. R.F. Taylor, E.W. Sharratt, L.E.M. de Chazal, D.H. Logsdail, J. Appl. Chem. 13, 32 (1963)

15. M. Benedict, T.H. Pigford, H.W. Levi, Nuclear chemical engineering (McGraw-Hill Education, 1981), 2nd ed.

16. J.B. Lefers, Absorption of nitrogen oxides into diluted and concentrated nitric acid, $\mathrm{PhD}$ thesis, Technische Universiteit Delft, 1980 
17. T. Fukasawa, Y. Ozawa, F. Kawamura, Nucl. Technol. 94, 108 (1991)

18. C. Delwaulle, A. Magnaldo, A. Salvatores, E. Schaer, J.-L. Houzelot, B. Rodier, E. Bossé, Chem. Eng. J. 174, 383 (2011)

19. C. Delwaulle, Étude de la dissolution du dioxyde d'uranium en milieu nitrique : une nouvelle approche visant à la compréhension des mécanismes interfaciaux, $\mathrm{PhD}$ thesis, Institut National Polytechnique de Lorraine, 2011

20. M. Shabbir, R.G. Robins, J. Appl. Chem. 19, 52 (1969)

21. Y. Ikeda, Y. Yasuike, Y. Takashima, Y.-Y. Park, Y. Asano, H. Tomiyasu, Nucl. Sci. Technol. 30, 118 (1993)

22. P. Berger, Étude du mécanisme de la dissolution par oxydoréduction chimique et électrochimique des bioxydes d'actinides $\left(\mathrm{UO}_{2}, \mathrm{NpO}_{2}, \mathrm{PuO}_{2}, \mathrm{AmO}_{2}\right)$ en milieu aqueux acides, $\mathrm{PhD}$ thesis, Université Paris VI, 1988

23. C. Brun, F. Valdivieso, M. Pijolat, M. Soustelle, Phys. Chem. Chem. Phys. 1, 471 (1999)

24. K.W. Song, K.S. Kim, Y.H. Jung, J. Nucl. Mater. 279, 356 (2000)

25. F. Grønwold, J. Inorg. Nucl. Chem. 1, 357 (1955)

26. H.D. Greiling, K.H. Lieser, Radiochim. Acta 35, 79 (1984)

27. A.L. Uriarte, R.H. Rainey, Dissolution of high-density $\mathrm{UO}_{2}$, $\mathrm{PuO}_{2}$ and $\mathrm{UO}_{2}-\mathrm{Pu} \mathrm{O}_{2}$ pellets in inorganic acids. Technical document Ref. ORNL-3695 (Oak Ridge National Laboratory, 1965)

28. A. Briggs, Dislocation etching and chemical polishing studies on $\mathrm{UO}_{2}$ single crystals. Technical document Ref. AERE-M 859 (United Kingdom Atomic Energy Authority, 1961)

29. A. Briggs, Br. Ceram. Trans. J. 60, 505 (1961)

30. M. Shabbir, R.G. Robins, J. Nucl. Mater. 25, 236 (1968)

31. M.R. Castell, S.L. Duradev, C. Muggelberg, A.P. Sutton, G. A.D. Briggs, D.T. Goddard, J. Vac. Sci. Technol. A 16, 1055 (1998)

32. C. Muggelberg, M.R. Castell, G.A.D. Briggs, D.T. Goddard, Surf. Sci. 402, 673 (1998)

33. C. Muggelberg, M.R. Castell, G.A.D. Briggs, D.T. Goddard, Appl. Surf. Sci. 142, 124 (1999)

34. E.-H. Kim, D.-S. Hwang, W.-M. Choung, J.-H. Park, J.H. Yoo, C.-S. Choi, Radiochim. Acta 83, 147 (1998)

35. Y. Zhao, J. Chen, J. Nucl. Mater. 373, 53 (2008)

36. Y. Zhao, J. Chen, Radiochim. Acta 96, 467 (2008)

37. Y. Zhao, J. Chen, Sci. China. Ser. B 51, 700 (2008)
38. T. Fukasawa, Y. Ozawa, J. Radioanal. Nucl. Chem. Lett. 106, 345 (1986)

39. J. Villermaux, Génie de la réaction chimique : conception et fonction-nement des réacteurs. Techniques et documentation - Lavoisier (1985)

40. O. Levenspiel, Chemical reaction engineering (Wiley, 1999), 3rd ed.

41. Y. Wada, K. Morimoto, H. Tomiyashu, Radiochim. Acta 72, 83 (1996)

42. J. Kumar Gelatar, B. Kumar, M. Sampath, S. Kumar, U. Kamachi Mudali, R. Natarajan, J. Radioanal. Nucl. Chem. 303, 1029 (2015)

43. B.F. Myasoedov, Y.M. Kulyako, J. Radioanl. Nucl. Chem. 296, 1127 (2013)

44. K. Nishimura, T. Chikazawa, S. Hasegawa, H. Tanaka, Y. Ikeda, Y. Ya-suike, Y. Takashima, J. Nucl. Sci. Technol. (Abingdon, U.K.) 32, 157 (1995)

45. Y. Yasuike, Y. Ikeda, M. Kumagai, K. Hoashi, Y. Takashima, S. Mat-sumoto, K. Nishimura, in Third International Conference on Nuclear Fuel Reprocessing and Waste Management. RECOD'91 Proceedings, Japan Atomic Industrial Forum, editor (1991), Vol. 2, pp. 692-697

46. M.J. Carrott, P.M.A. Cook, O.D. Fox, C.J. Maher, S.L.M. Schroeder, Proc. Chem. 7, 92 (2012)

47. E.-H. Kim, D.-S. Hwang, J.H. Yoo, J. Radioanal. Nucl. Chem. 245, 567 (2000)

48. S. Homma, J. Koga, S. Matsumoto, T. Kawata, J. Nucl. Sci. Technol. (Abingdon, U.K.) 30, 956 (1993)

49. A. Inoue, J. Nucl. Mater. 138, 152 (1986)

50. A. Inoue, Nucl. Technol. 90, 186 (1990)

51. L. Claparede, F. Tocino, S. Szenknect, A. Mesbah, N. Clavier, N. Dacheux, J. Nucl. Mater. 457, 304 (2015)

52. N. Desigan, E. Augustine, R. Murali, N.K. Pandey, U. Kamachi Mu-dali, R. Natarajan, J.B. Joshi, Prog. Nucl. Energy 83, 52 (2015)

53. Y. Ikeda, Y. Yasuike, Y. Takashima, K. Nishimura, H. Tomiyasu, J. Nucl. Sci. Technol. (Abingdon, U.K.) 30, 485 (1993)

54. F. Tocino, S. Szenknect, A. Mesbah, N. Clavier, N. Dacheux, Prog. Nucl. Energy 72, 101 (2014)

55. M.M. Mbogoro, M.E. Snowden, M.A. Edwards, M. Peruffo, P.R. Unwin, J. Phys. Chem. C 115, 10147 (2011) 